\title{
Determination of Chromium and Other Trace Elements from North Western Nigeria by Proton Induced X-ray Emission Technique
}

\author{
Bello Abdullahi ${ }^{1}$, M. T. Tsepav ${ }^{1}$, M. D. Oladipupo ${ }^{1} \&$ B. Alfa $^{1}$ \\ ${ }^{1}$ Department of Physics, IBB University Lapai, Niger State, Nigeria \\ Correspondence: Bello Abdullahi, Department of Physics, IBB University Lapai, Niger State, Nigeria. Tel: \\ 234-80-3072-3338. E-mail: bello.abdullahi455@gmail.com
}

\author{
Received: February 22, $2012 \quad$ Accepted: June 20, $2012 \quad$ Online Published: June 26, 2012 \\ doi:10.5539/mas.v6n7p96 \\ URL: http://dx.doi.org/10.5539/mas.v6n7p96
}

\begin{abstract}
Proton induced X-ray emission (PIXE) was used in the analyses of geological samples to determine accurate deposits of chromium and other trace elements. Fourteen samples were collected from sites suspected to have chromium deposits, then prepared to the required standard to be interrogated by the above technique. Samples were irradiated at Centre for Energy Research and Development, Ile-Ife, Nigeria. From the Spectra and results generated, it suggests significant deposits of Chromium in some regions of Nigeria. Gold deposit was observed to be significant in some areas. Concentrations of $\mathrm{Pb}, \mathrm{Si}, \mathrm{P}, \mathrm{S}, \mathrm{K}, \mathrm{Ca}, \mathrm{Ti}, \mathrm{V}, \mathrm{Cr}$ and $\mathrm{Mn}$ elements were determined as well.
\end{abstract}

Keywords: proton induced X-ray emission (PIXE), chromium

\section{Introduction}

The need for chromium in steel industries cannot be overemphasized, particularly now that the Ajaokuta Steel Industries in Nigeria is about to resume production after a long time in comatose. Chromium is a relatively common element with an average concentration of $100 \mathrm{ppm}$. It is the $21 \mathrm{st}$ most commonly occurring element in the earth's crust. For its production one does not require the pure metal. Pure chromium is obtained by reduction of chromium oxide with aluminium, by electrolysis, or via chromium iodide. About $10 \%$ of chromium consumed originates from recycling; mainly from scrap steel (Saager, 1984). Chromium compounds are used in the chemical industry in various fields. The metal industry uses most of the chromium in the form of master alloys, preferably in special steels (stainless steel). In the galvanizing industry other metals are coated with a chromium layer in an electrolytic process in which chromium is deposited from a sulfuric acid-chromate solution (El-Taher, 2010). Additional applications of chromium compounds are found in the following: building industry (as pigments), printing industry (photomechanical reproduction processes), oil industry (as anti-corrosives), textile industry (chromium mordant for textiles and chrome dyeing processes), match industry and fireworks (additive to the inflammable mixture). In the cassette tape industry chromium oxide is used in a specially crystallized form.

This work is concerned with the use of proton induced X-ray emission to achieve an accurate knowledge of the chromium content and other trace elements in North Western Nigeria (Ahmed, 2004).

\section{Materials and Analytical Methods}

The aim of this study was to characterize fourteen rock samples that were collected from different regions of North Western Nigeria.

Samples were crushed to small pieces using a mechanical crusher. The crushed samples were dried at $105^{\circ} \mathrm{C}$ to constant weight. The dried samples were ground to form fine powder. Then the powdered samples were sieved using a standard set of sieves to a diameter range of less than 125 . Every powdered sample was shaken using an electric shaker to be sure that the sample was homogenized. From each of the fourteen balk samples, pellets were made by hydraulic press ( 3 ton). Standards (NIST 278, BCS 355) were irradiated by thick target proton induced X-ray emission (CERD) with $2.5 \mathrm{MeV}$ and $3.0 \mathrm{MeV}$ proton beams accelerator for accuracy and validation. The proton beam was collimated. Characteristic X-ray were measured by three detectors, one detector was placed at $45^{\circ}$ for PIXE, the other at $135^{\circ}$ for Rutherford backscattering spectroscopy (RBS) and the third detector was for proton induced gamma ray emission (PIGE). Table 1 display the quality control from the standard reference 
material (SRMs) (Graham et al., 2002). Thereafter the pellets were subjected to same analytical conditions as the SRMs, subsequently analyzed by GUPIX (a program for the non-linear least-squares fitting of P1XE spectra).

Table 1. Elemental concentrations (ppm) in selected reference materials using PIXE

\begin{tabular}{|c|c|c|c|c|}
\hline \multirow[b]{2}{*}{ Analyte } & \multicolumn{2}{|c|}{ NIST 278 (Obsidian rock) } & \multicolumn{2}{|c|}{$\mathrm{BCS} 355$ (Tin ore) } \\
\hline & Reported value & This work & Reported value & This work \\
\hline $\mathrm{Si}$ & 341436 & $342392.3 \pm 9039$ & 5000.0 & $5152.6 \pm 484$ \\
\hline $\mathrm{Cl}$ & NA & $609.1 \pm 140$ & NA & $321.3 \pm 187$ \\
\hline $\mathrm{K}$ & 3453 & $3465.8 \pm 148$ & $-N A$ & $3215.6 \pm 562$ \\
\hline $\mathrm{Ca}$ & 7025 & $7057.4 \pm 114$ & 2630 & $2688.5 \pm 528$ \\
\hline $\mathrm{Ti}$ & 1468 & $1475.9 \pm 30$ & 3700 & $3693.7 \pm 76$ \\
\hline $\mathrm{Mn}$ & 403 & $378.8 \pm 15$ & NA & $1795.6 \pm 39$ \\
\hline $\mathrm{Fe}$ & 14268 & $14321 \pm 72$ & 170800 & $170282.8 \pm 255$ \\
\hline $\mathrm{Cu}$ & 5.9 & $6.4 \pm 7.3$ & 850 & $848.8 \pm 35$ \\
\hline $\mathrm{Zn}$ & 55 & $56.4 \pm 17.3$ & 590 & $589.5 \pm 32$ \\
\hline $\mathrm{Rb}$ & 127.5 & $127.8 \pm 21$ & - & - \\
\hline $\mathrm{Zr}$ & NA & $265.3 \pm 48$ & - & - \\
\hline $\mathrm{Cr}$ & - & - & NA & $60.7 \pm 25$ \\
\hline As & - & - & 1400 & $1398.5 \pm 50$ \\
\hline $\operatorname{Sn}(\mathrm{K})$ & - & - & 314200 & $314901.4 \pm 4881$ \\
\hline $\operatorname{Sn}(L A)$ & - & - & 314200 & $314969.2 \pm 1134$ \\
\hline $\mathrm{Ba}$ & 1140 & $1144.1 \pm 229$ & - & - \\
\hline $\mathrm{Ce}$ & 62.2 & $65 \pm 32$ & - & - \\
\hline $\mathrm{Cd}$ & - & - & $N A$ & $1070 \pm 577$ \\
\hline $\mathrm{W}$ & & - & 3500 & $3491.7 \pm 152$ \\
\hline
\end{tabular}

\section{NA: Not analyzed.}

\subsection{PIXE Calculations}

The formula for calculating concentration $[Y(Z)]$ in PIXE is given as:

$$
Y(Z)=\frac{N_{a v} \omega_{Z} b_{Z} t_{Z} \varepsilon_{Z}^{i} \Omega / 4}{A_{Z}} N_{p} C_{Z} \int_{E_{0}}^{E_{f}} \frac{\sigma_{Z}(E) T_{2}(E)}{S_{M}(E)} d E
$$

Where $N_{p}$ is the number of protons, Nav Avogadro's number, and $\sigma_{z}$ (E) the K-shell ionization cross section for the proton energy $\mathrm{E}$ corresponding to depth $\mathrm{x}$. The number of $\mathrm{K}$ X-rays in a particular spectral line is then obtained via the fluorescence yield $\omega_{k, z}$ and line intensity fraction $b_{k, z}$. 
If we generalized angle $\alpha$ and $\Theta_{T O}$ for proton impact and X-ray take off en route to the detector, the X-ray intensity from the element of the path indicated suffers a transmission factor.

When specimens are thick enough to stop the beam, then we have $E_{f}=0$ in Eq. 1. The matrix (M) effect (i.e., those due to proton slowing and X-ray attenuation) are contained in the integral, which we denoted by $I_{Z}(M)$ where $\mathrm{M}$ denotes the specimen (SP) or the standard (ST).

$$
\frac{C_{Z}(S P)}{C_{Z}(S T)}=\frac{Y_{Z}(S P)}{Y_{Z}(S T)} \frac{I_{Z}(S T)}{I_{Z}(S P)}
$$

Standards are usually single elements or very simple compounds containing the elements of interest or their near neighbors in the chart of nuclides.

The merit of this ratio process is its cancellation of instrumental factors such as solid angle, efficiency, and calibration factors for charge integration (Aung, 2002). This is important given the practical difficulties in obtaining accurate knowledge of the detector's lineshape and intrinsic efficiency at the low X-ray energies characteristic of the light elements that are so often the major elements in environmental specimens (Sven, 1995).

\section{Results and Discussion}

We have reported data only for $\mathrm{Pb}, \mathrm{Si}, \mathrm{P}, \mathrm{S}, \mathrm{K}, \mathrm{Ca}, \mathrm{Ti}, \mathrm{V}, \mathrm{Cr}$ and Mn elements; however trace elements like Au were significantly detected in the pellets. $\mathrm{Cr}$ is found in all the samples; however we should be quick to point out that it is only at sites of samples C, D, I, J, k, L, M, N and Q that Cr can be mined profitably while sites A, B and $\mathrm{D}$ require further research to be undertaken before exploitation. Figure 2 clearly indicated energypeaks for chromium as well as other elements. Lead $(\mathrm{Pb})$ was unusually above the normal in this region; that probably explains the recent epidemic of Lead poisoning in children. World Health Organization (WHO) had to intervene to arrest the scourge. From Figure 1, the three energypeak of $\mathrm{Pb}$ displayed in the spectra shows that Lead is quite significant compared to other elements in this pellets. $\mathrm{Pb}$ energypeaks were replicated in all the spectra as the one discussed above. Only in two samples that Lead was found to be below detection. Further research is recommended for the promising sites. Table 2 depicts the concentrations of the all elements alongside research errors.

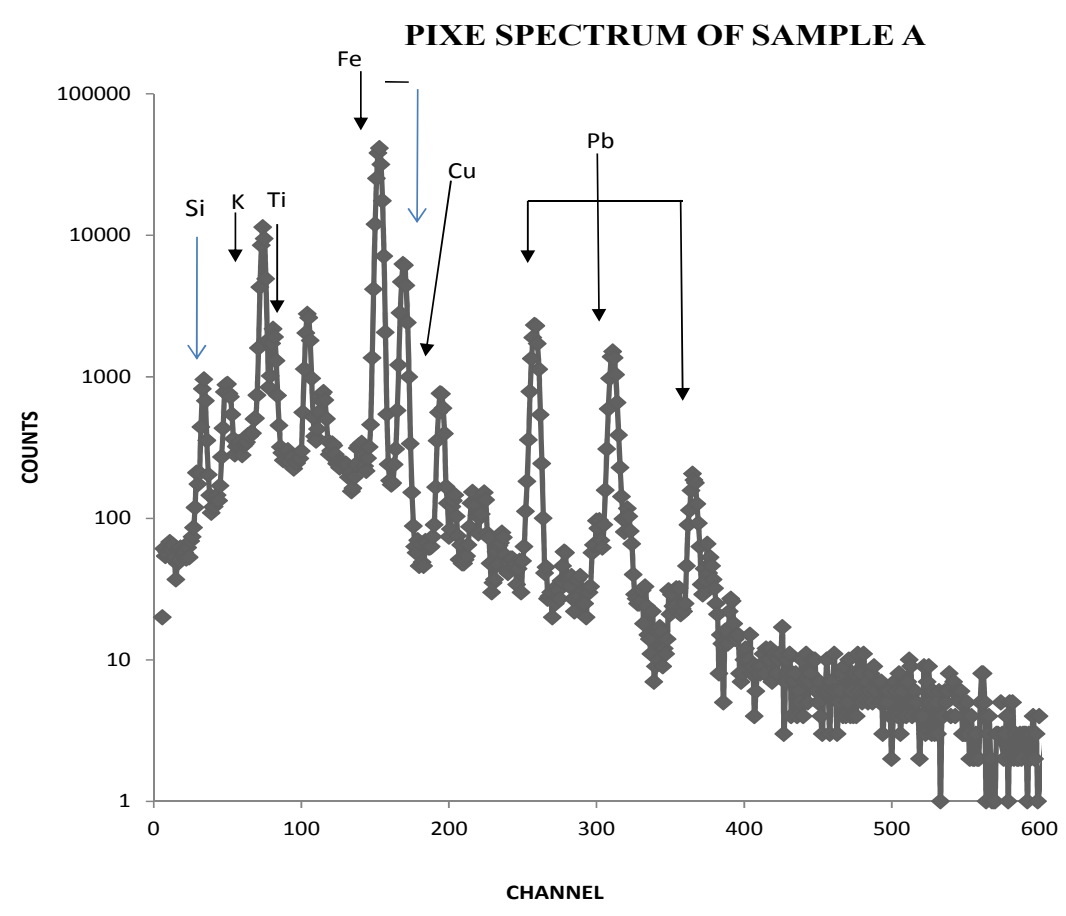

Figure 1. X-ray spectrum of Sample A (Pellet A) 


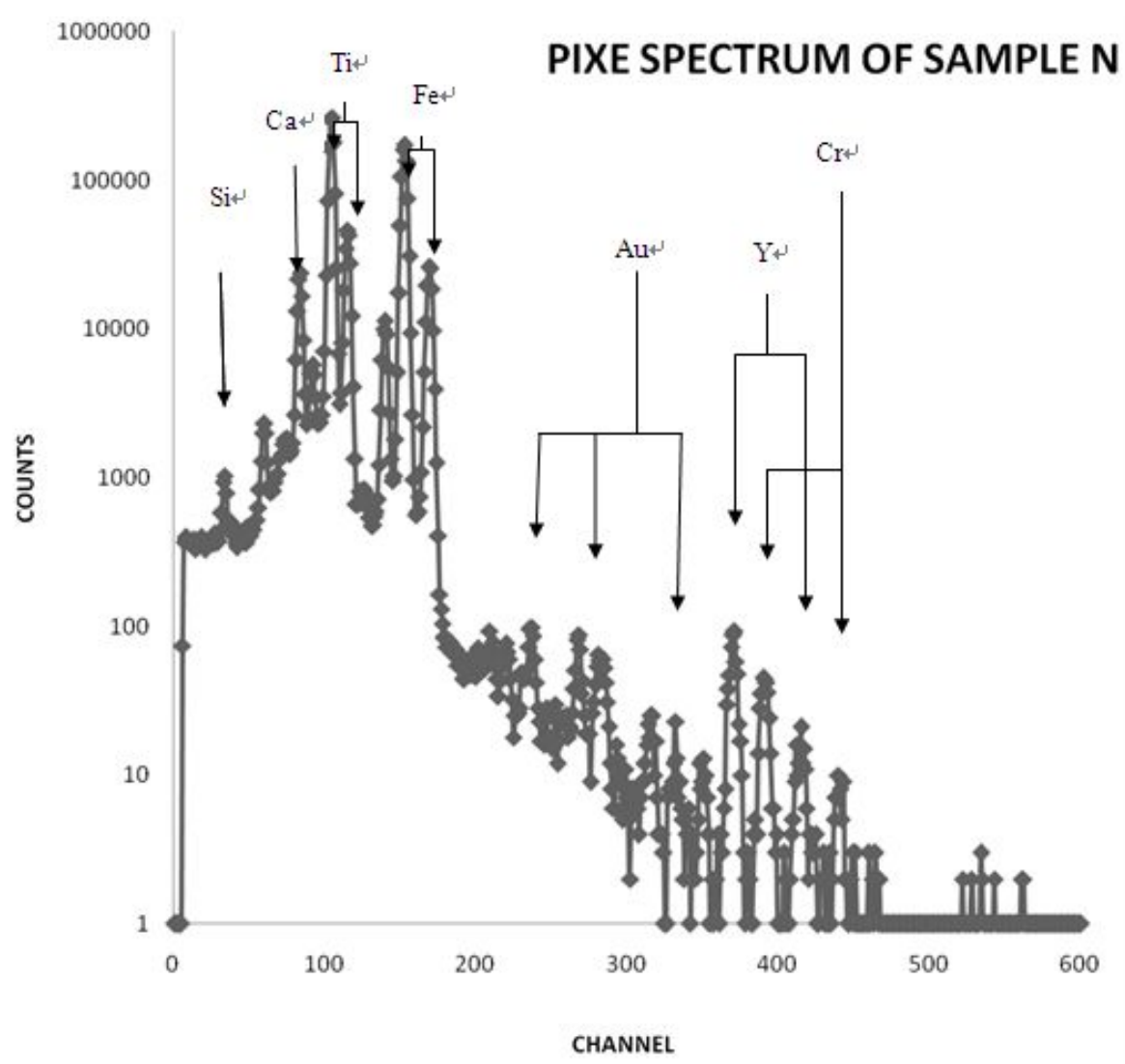

Figure 2. X-ray spectrum of sample $\mathrm{N}$

Table 2. Average concentration of elements in the samples (Pellets)

\begin{tabular}{|c|c|c|c|c|c|c|c|c|c|c|}
\hline & $\mathrm{Fb}$ & si & $p$ & s & K & $\mathrm{Ca}$ & $\pi$ & v & $a$ & Mn \\
\hline A & $46460.2 \pm 483$ & $377416.5 \pm 9473$ & $2077.8 \pm 1043$ & $8376.2 \pm 552$ & $20708.1 \pm 128$ & $289.1 \pm 66$ & $2310.8 \pm 43$ & $74.5 \pm 29$ & $49.2 \pm 16$ & $188.1 \pm 18$ \\
\hline B & $15932.7 \pm 287$ & $550391.8 \pm 9522$ & $1586.4 \pm 730$ & $2388 \pm 370$ & $\mathrm{BDL}$ & $99.9 \pm 29$ & $235.2 \pm 19$ & $\mathrm{BOL}$ & $52.3 \pm 11$ & $\mathrm{EOL}$ \\
\hline c & $5379.9 \pm 170$ & $394457.3 \pm 8047$ & $2075.5 \pm 707$ & 6124250 & $4525.3 \pm 55$ & $320.2 \pm 32$ & $819.7 \pm 23$ & $55.4 \pm 18$ & $403.9 \pm 17$ & $3944.5 \pm 35$ \\
\hline D & $128.2 \pm 60$ & $582448.6 \pm 13338$ & $\mathrm{BOL}$ & $\mathrm{BOL}$ & $1274.2 \pm 68$ & $31327.5 \pm 122$ & $129814 \pm 206$ & $\mathrm{EOL}$ & $260.8 \pm 22$ & $6023.6 \pm 52$ \\
\hline $\mathrm{E}$ & $50332.1 \pm 438$ & $343277.2 \pm 8033$ & $\mathrm{BOL}$ & $8760.2 \pm 498$ & $19458.1 \pm 111$ & $208.2 \pm 62$ & $2397.3 \pm 36$ & $53 \pm 24$ & $77.9 \pm 16$ & $\mathrm{EOL}$ \\
\hline G & $655.5 \pm 86$ & $341083.5 \pm 12825$ & $\mathrm{BDL}$ & $\mathrm{BOL}$ & $1401.5 \pm 60$ & $4581.4 \pm 57$ & $232362.9 \pm 232$ & $\mathrm{EOL}$ & $346 \pm 29$ & $11958.6 \pm 67$ \\
\hline 1 & $11216.7 \pm 208$ & $365260.6 \pm 7707$ & $1652.1 \pm 763$ & $3850.2 \pm 322$ & $22414.7 \pm 110$ & $384.9 \pm 62$ & $2905.4 \pm 33$ & $262 \pm 24$ & $206.3 \pm 14$ & $113 \pm 13$ \\
\hline J & $32087.7 \pm 347$ & $367964.5 \pm 7948$ & $34484 \pm 841$ & $5997.6 \pm 430$ & $15251.4 \pm 96$ & $422.5 \pm 51$ & $2715.1 \pm 35$ & $104.9 \pm 25$ & $118 \pm 16$ & $1265.9 \pm 24$ \\
\hline$k$ & $\mathrm{EOL}$ & $243974.5 \pm 16249$ & $\mathrm{BOL}$ & $\mathrm{BCL}$ & $631 \pm 68$ & $8054 \pm 69$ & $360244.9 \pm 288$ & $\mathrm{EOL}$ & $663.1 \pm 38$ & $20015 \pm 90$ \\
\hline $\mathrm{L}$ & $18591.8 \pm 268$ & $411887.3 \pm 8032$ & $2514.6 \pm 732$ & $3910.4 \pm 340$ & $10626.1 \pm 79$ & $370 \pm 42$ & $915.3 \pm 28$ & $67.9 \pm 21$ & $102.2 \pm 13$ & $1639.8 \pm 13$ \\
\hline$M$ & $40918 \pm 393$ & $334759.7 \pm 7807$ & $4704.3 \pm 922$ & $8514 \pm 467$ & $29259 \pm 129$ & $323.5 \pm 76$ & $3668.7 \pm 40$ & $209.3 \pm 28$ & $113.4 \pm 15$ & $201.3 \pm 16$ \\
\hline $\mathrm{N}$ & $165.2 \pm 82$ & $539773.8 \pm 16733$ & $\mathrm{BOL}$ & $\mathrm{BCL}$ & $1281 \pm 82$ & $44195.4 \pm 141$ & $233525.2 \pm 280$ & $1492.5 \pm 493$ & $290 \pm 36$ & $14859.6 \pm 85$ \\
\hline$p$ & $\mathrm{EOL}$ & $358373.9 \pm 15088$ & $\mathrm{BOL}$ & $\mathrm{BOL}$ & $1511.2 \pm 71$ & $9172.8 \pm 79$ & $231040 \pm$ & $\mathrm{EOL}$ & $295 \pm 34$ & $10994.2 \pm 75$ \\
\hline a & $59.2 \pm 54$ & $169638.3 \pm 10416$ & $\mathrm{BOL}$ & $\mathrm{BCl}$ & $681 \pm 45$ & $8490.2 \pm 58$ & $136234.4 \pm 164$ & $\mathrm{EOL}$ & $2455.1 \pm 32$ & $9017.9 \pm 61$ \\
\hline
\end{tabular}

From the values tabulated in Table 1, the effectiveness and accuracy of PIXE method (within $\pm 5.0 \%$ ) was evaluated and validated. Figure 1 depicts the X-ray spectrum of some of the elements in sample A in their 
various channels. It can be deducted from this figure that concentrations of elements can be speculated from the heights of energypeaks.

\section{Conclusion}

From the obtained results, it appears that PIXE can provide useful data with a satisfactory accuracy and precision. Table 2 shows that sample Q has promising concentration of $\mathrm{Cr}$ compared to other samples. This site is recommended for further investigations. Samples A, B and E are below the average concentration of $100 \mathrm{ppm} . \mathrm{Pb}$, $\mathrm{Ca}, \mathrm{Ti}$, and $\mathrm{Mn}$ are the major elements after Cr. Particularly Lead $(\mathrm{Pb})$ is observed to be oddly high in some of the samples. This confirms the rife cases of Lead $(\mathrm{Pb})$ poisoning being experienced in North Western Nigeria. Many children have died, and many others are suffering debilitating illnesses associated with Lead $(\mathrm{Pb})$ poisoning.

\section{References}

Ahmed, M. (2004). Analysis of geological samples by the micro-PIXE facility at KFUPM. Journal of Radioanalytical and Nuclear Chemistry, 265(1), 39-45. http://dx.doi.org/10.1007/s10967-005-0786-6

Aung, P., Siegele, R., Cohen, D. D., Stelcer, E., \& van Moort, J. C. (2002). Proton induced X-ray emission and proton induced gamma ray emission in geochemical exploration for gold and base metal deposits. Nuclear instruments and Methods in physics research B, 190, 501-504. http://dx.doi.org/10.1016/S0168-583X(01)01196-X

El-Taher, A. (2010). Determination of chromium and trace elements in El-Rubish chromite from eastern desert, Egypt by neutron activation analysis. Applied radiation and isotopes, 68(1864-1868). http://dx.doi.org/10.1016/j.apradiso.2010.04.018

El-Taher, A., Kratz, K. L., Nossair, A., \& Azzam, A. H. (2003). Determination of gold in two Egyptian gold ores using instrumental neutron activation analysis. Radiation physics and chemistry, 68(751-755). http://dx.doi.org/10.1016/S0969-806X(03)00401-8

Graham, C. W., John, C. R., John, L. C., Zdenek, N., \& William, J. T. (2002). Application of PIXE to mineral characterization. Nuclear instruments and methods in physics research B, 189(387-393). http://dx.doi.org/10.1016/S0168-583X(01)01095-3

Rodriguez-Fernandez, L., Miranda, J., Ruvalcaba-Sil, J. L., Segundo, E., \& Oliver, A. (2002). Measurement of M-shell X-ray production induced by protons of $0.3-0.7 \mathrm{MeV}$ on $\mathrm{W}, \mathrm{Au}, \mathrm{Pb}, \mathrm{Bi}$, Th and $\mathrm{U}$. Nuclear Instruments and Methods in Physics Research B, 189, 27-32. http://dx.doi.org/10.1016/S0168-583X(01)00989-2

Saager, R. (1984). Metallic Raw Materials Dictionary (in German). Bank von Tobel, Zurich, Switzerland, pp. 113-117.

Sven, A. E. J., John, L. C., \& Klaus, G. M. (1995). Particle-induced X-ray Emission Spectrometry (PIXE), 133.

Wierzchos, J., Ascaso, C., Ager, F. J., Garcia, O., Carmona-Luque, A., \& Respaldiza, M. A. (2006). Identifying elements in rocks from the dry Valleys desert (Antartica) by ion beam proton induced X-ray emission. Nuclear Instruments and Methods in Physics Research B, 249, 571-574. http://dx.doi.org/10.1016/j.nimb.2006.03.057 